\title{
MIGRAÇÃO, CIDADANIA E DIREITOS FUNDAMENTAIS NA TRÍPLICE FRONTEIRA ${ }^{1}$
}

\section{MIGRATION, CITIZENSHIP AND FUNDAMENTAL RIGHTS IN TRIPLE FRONTIER ${ }^{2}$}

\author{
Ane Elise Brandalise Gonçalves ${ }^{3}$ \\ Eduardo Biacchi Gomes ${ }^{1}$ \\ Francisco Cardozo Oliveira ${ }^{1}$
}

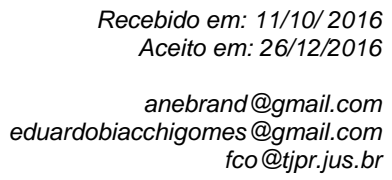
fco@tjpr.jus.br

\begin{abstract}
Resumo: O presente trabalho visa ao estudo das migrações e dos correlatos direitos fundamentais devidos sob o olhar da Tríplice Fronteira e de sua vivacidade em termos de cultura e identidade. Para tanto, duas ideias centrais são explanadas no artigo, quais sejam: (a) a normatividade dos direitos de cidadania na região da Triplice Fronteira deve considerar os desdobramentos da realidade socioeconômica, das relações sociais no território, do encontro com o outro e da interação de culturas, sem que a fusão, a mistura de relações, de visões e de sinais seja visto como algo negativo; (b) a proteção dos direitos de cidadania das pessoas na Triplice Fronteira se desdobra a partir da configuração material dos conflitos em torno da luta por reconhecimento de direitos de migrantes. Para tanto, o artigo apresenta, em um primeiro instante, a questão de territórios e fronteiras; a realidade socioeconômica da região da Tríplice Fronteira e, por fim, estuda o reconhecimento dos direitos fundamentais aos migrantes da região. O trabalho utilizouse de um método multidisciplinar, cunhado não só pelo Direito, mas também por meio de outras áreas do saber (com destaque para Antropologia, Economia e Relações Internacionais).
\end{abstract}

Palavras-chave: Migrações. Tríplice Fronteira. Direitos Fundamentais. Cidadania.

Abstract: This work aims to study the migration and related fundamental rights due under the gaze of the Triple Frontier and its vivacity in terms of culture and identity. Therefore, two central ideas are explained in the article, namely: (a) the normativity of citizenship rights in the region the Triple Frontier should consider the consequences of the economic reality, social relations in the territory, the encounter with the other and the interaction cultures, without the merger, the mixing ratios, visions and signs to be seen as something negative; (b) the protection of people citizenship rights in the Triple Border unfolds from the material configuration of conflicts around the struggle for recognition of migrant rights. Therefore, the article presents, in the first instance, the question of territories and borders; the socioeconomic reality of the Triple Border region and, finally, studies the recognition of fundamental rights for migrants in the region. The study used a multidisciplinary method, coined not only by Law but also through other areas of knowledge (especially Anthropology, Economics and International Relations).

Keywords: Migrations. Triple Frontier. Fundamental rights. Citizenship.

\section{INTRODUÇÃO}

\footnotetext{
${ }^{1}$ A pesquisa que deu ensejo ao presente artigo iniciou-se através da apresentação, realizada em 26 de setembro de 2014, proferida pelo Exmo. Juiz Francisco Cardozo Oliveira na Ordem dos Advogados do Brasil, seccional Paraná (OAB/PR) - subseção Foz do Iguaçu, versando sobre temas de Direito de Fronteira e intitulada "Migração, respeito à pessoa e direitos de cidadania".

${ }^{2}$ The research that gave rise to this article began by presenting held on September 26, 2014, issued by the Hon. Judge Cardozo Francisco Oliveira in the Order of Lawyers of Brazil, sectional Paraná (OAB/PR) - subsection Foz do Iguaçu, dealing with issues of law and Border entitled "Migration, respect for the person and citizenship rights".

${ }^{3}$ Centro Universitário Autônomo do Brasil - UniBrasil - Curitiba - Paraná
} 
Os fluxos migratórios colocam em questão fronteiras: o território, o encontro com o outro e a interação de culturas. Conforme assinala Leonora Corsini, a associação entre fronteiras e migração não tem o sentido apenas de divisa e de separação, mas de lugar do encontro e de possibilidades (Fronteiras, atravessamentos e deslocamentos: desenhando novas cidadanias) ${ }^{4}$. Não obstante as infinitas possibilidades que traz, a migração, mormente em tempos atuais, tem-se constituído uma espécie de verdadeiro "cosmodrama vestefaliano" - conforme expressão de Richard Falk ${ }^{5}$, que impõe novas formas de análise e compreensão para além da seara puramente jurídica e para além das fronteiras estatais.

Nessa toada, à luz do relacionamento do Direito Internacional dos Direitos Humanos com o plano do ser, ou seja, com a migração na esfera latinoamericana e, mais especificamente, da migração ocorrida na Tríplice Fronteira (aqui entendida como o local que delimita Brasil, Argentina e Paraguai), o presente artigo tem como propósito analisar o alcance da normatividade da proteção dos direitos humanos dos migrantes, nos termos de luta por reconhecimento de direitos, no contexto da realidade social, cultural e econômica da Tríplice Fronteira, sendo o problema científico ora analisado a questão migratória em determinada região (Tríplice Fronteira) e os direitos inerentes aos migrantes.

Para tanto, o percurso do presente artigo perpassa por três eixos de análise, quais sejam: (a) migração, cultura e a questão do respeito à pessoa, que se desdobra em território e trânsito de pessoas, fronteiras e o encontro do outro e cultura de fronteira; (b) realidade socioeconômica da Tríplice Fronteira de Foz do Iguaçu, desdobrada em realidade social, realidade econômica e violência; (c) reconhecimento, dignidade e direitos de cidadania na fronteira, desdobrado em alcance da normatividade dos direitos humanos dos migrantes e pressupostos da luta por reconhecimento de direitos dos migrantes, como um verdadeiro direito humano de tez universal, entendido aqui como não como algo estático, mas, sim, como "os processos, as dinâmicas de lutas históricas decorrentes de resistências contra a violência que as diferentes manifestações do poder do capital exerceram contra os indivíduos e coletivos"6.

Nessa linha de raciocínio, constata-se que a normatividade que gira em torno da questão migratória depende de variados fatores, de transformação e ação, de um mundo construído por todos e no qual não se deve mais contar apenas com o Estado como agente, mas, sim, deve-se depender das escolhas, valores e crenças, aptas a ajudar nesta construção mundial em prol da dignidade da pessoa humana.

Desta feita, o paradigma metodológico é imanente e de reconstrução dos processos de construção da socialidade e de identificação de obstáculos na vida social das pessoas na fronteira.

\section{O TERRITÓRIO E TRÂNSITO DE PESSOAS}

\footnotetext{
${ }^{4}$ CORSINI, Leonora. Fronteiras, atravessamentos e deslocamentos: desenhando novas cidadanias. In: Fronteiras e diversidades culturais no século XXI: desafios para o reconhecimento no estado global. Maciel, Tania Barros; Neto, Maria Inácia Davila; Andrade, Regina Glória(Org), FAPERJ, Rio de Janeiro, 2012.

${ }^{5}$ FALK, Richard. Globalização Predatória: uma crítica. Trad. de Rogério Alves. Lisboa: Instituto Piaget, 1999, p. 52.

${ }^{6}$ FLORES, Joaquim Herrera; A (re)invenção dos direitos humanos. Florianópolis: Fundação Boiteux, 2009, p.169.
} 
Os fluxos migratórios colocam em questão fronteiras: o território, o encontro com o outro e a interação de culturas. Conforme assinala Leonora Corsini, a associação entre fronteiras e migração não tem o sentido apenas de divisa e de separação, mas de lugar do encontro e de possibilidades (Fronteiras, atravessamentos e deslocamentos: desenhando novas cidadanias) ${ }^{7}$.

De outra banda, apesar das infinitas possibilidades que traz, a migração, mormente em tempos atuais, tem-se constituído uma espécie de verdadeiro "cosmodrama vestefaliano" (conforme expressão de Richard Falk ${ }^{8}$, ao estudar o fenômeno da Globalização), que impõe novas formas de análise e compreensão para além da seara puramente jurídica e para além das fronteiras estatais.

Com efeito, a globalização econômica reduziu as barreiras entre Estados nacionais, bem como constitui-se em elemento explicativo para os mais diversos fluxos migratórios, mas ainda mantém limites de trânsito de pessoas entre países diferentes. Portanto, contanto que ainda subsista o sistema vestefaliano estatal, faz-se necessária a compreensão de fronteira e território.

No presente ensaio toma-se o território a partir de uma perspectiva interdisciplinar, no sentido pensado por Milton Santos, de condensação no espaço de técnicas e habilidades ${ }^{9}$.

Ainda assim, acerca do tema "território", cabe ressaltar que não falta na literatura da Geopolítica, ramo do conhecimento que dialoga com as Relações Internacionais, entendimentos sobre o tema fronteira e território, que vão desde concepções naturalistas, em que território e fronteira fundem-se com as características naturais e ambientais do local, até concepções de caráter póscolonial que visam afastar-se das visões eurocêntricas e reconhecer espaços, como a América Latina, como importantes centros de poder ${ }^{10}$.

No ponto, apesar do reconhecimento da importância da visão dos Países concentrados no Sul geográfico para conjuntura e cenário internacional, ainda a América Latina, constituída por países periféricos e semi-periféricos ${ }^{11}$, vive intensos fluxos migratórios territoriais, mormente por parte de populações marginalizadas, resultantes da escassez de oportunidades de vida digna, a exemplo do que ocorre no México em direção aos Estados Unidos, ou, mais próximo da nossa realidade, com os haitianos em direção ao Brasil.

A fronteira de Foz do Iguaçu, em termos de relação entre migração e território, contempla uma solução típica da semiperiferia do sistema mundo ocidental, para usar a definição de Imannuel

\footnotetext{
${ }^{7}$ CORSINI, Leonora. Fronteiras, atravessamentos e deslocamentos: desenhando novas cidadanias. In: Fronteiras e diversidades culturais no século XXI: desafios para o reconhecimento no estado global. Maciel, Tania Barros; Neto, Maria Inácia Davila; Andrade, Regina Glória(Org), FAPERJ, Rio de Janeiro, 2012.

${ }^{8}$ FALK, Richard. Globalização Predatória: uma crítica. Trad. de Rogério Alves. Lisboa: Instituto Piaget, $1999, \mathrm{p}$. 52.

${ }^{9}$ SANTOS, Milton. Natureza do espaço; técnica e tempo, razão e emoção. 3.ạed., São Paulo, Hucitec. 1999.

${ }^{10}$ CAIRO, Heriberto. A América Latina nos modelos geopolíticos modernos: da marginalização à preocupação com sua autonomia. Caderno CRH, vol.21, n.53 Salvador Mai/Ago 2008. Disponível em: <http://dx.doi.org/10.1590/S0103-49792008000200003>. Acesso em: 02 fev 2016.

${ }^{11}$ A noção de países-centro e países periféricos remonta às ideias da teoria crítica de Wallerstein, de Robert Cox e de Gramsci. Destaque para Immanuel Wallestein como o grande teórico da ideia de "sistema-mundo", segundo a qual o capitalismo é a base econômica deste sistema e cuja estrutura mundial pode ser classificada em países centro, semi-periferia e periferia.
} 
Wallerstein $^{12}$, de combinação de repressão policial, em torno da proteção de mercados e de mercadorias, produtos e bens, e de liberalização do tráfego de pessoas.

Nesse sentido, também as percepções do antropólogo Ulf Hannerz ${ }^{13}$

É verdade que a história acumula correntes de fluxo cultural em padrões cambiantes. Esse complexo de assimetrias tomou forma séculos atrás na Europa, e, tendo-se acelerado neste século, também criou por si mesmo algumas das condições para os posteriores contrafluxos e fluxos entrecruzados no espaço que hoje nos parecem tão admiráveis. Duvido, porém, que tenhamos chegado ao ponto em que seja completamente impossível distinguir os centros das periferias

Ou seja, em termos de migração e fronteiras configura-se uma dinâmica no sentido de que, enquanto a relação periferia-centro do sistema mundo ocidental privilegia os acordos de livre comércio combinado com o trânsito seletivo de pessoas, a relação entre países semiperiféricos privilegia o livre trânsito de pessoas combinado com a tráfego seletivo de bens e serviços.

Os dados da Anistia Internacional, no Informe 2014/2015 - O Estado dos Direitos Humanos no Mundo, bem ilustram a situação: o ano de 2015 contou com mais de 19 milhões só de pessoas consideradas juridicamente $\operatorname{como}_{\text {refugiados }}{ }^{14}$, sendo que $85 \%$ desses vão para países semiperiféricos e apenas 15\% são repartidos entre Europa e América (Estados Unidos e Canadá) ${ }^{15}$. Observa ainda a Anistia que a ineficiência, a inação, por parte de alguns Estados centrais ou mesmo o tratamento desses países de desprezo, violência ou proibição para com os refugiados, tem contribuído para a multiplicação das violações contra direitos humanos ${ }^{16}$.

Assim, na experiência da Comunidade Econômica Europeia, por exemplo, apesar do livre fluxo entre países para cidadão europeus, ainda pode-se observar severas exigências no trânsito de pessoas de outras regiões do mundo, sem contar que os fluxos migratórios em direção à Europa revigoram sentimentos xenófobos com repercussões políticas. O número de migrantes e refugiados, segundo a Anistia Internacional, possui dados alarmantes, mas de respostas pouco viáveis por parte da União Européia ${ }^{17}$.

Mais próximo ainda da realidade regional da América Latina, tem-se que a migração latinoamericana em direção aos Estados Unidos renovou, de forma perversa, o ímpeto de construção de

\footnotetext{
${ }^{12}$ WALLERSTEIN, Immanuel Maurice. The modern world-system: capitalism, agriculture and the origins of the European World-Economy in the sixteenth century. New York: Academic Press, 1974.

${ }^{13}$ HANNERZ, UIf. Fluxos, Fronteiras, Híbridos: palavras-chave da antropologia transnacional. Mana - Estudos de Antropologia Social, vol. 3, n. 1.Rio de Janeiro, Contracapa, abril, p. 07-39, 1997, p. 14.

${ }^{14}$ Sem adentrar de forma profunda na discussão que orbita em torno da confusão entre conceitos de migração e refúgio, cabe colocar que a questão entre a conceituação jurídica de refugiado, e sua relação com a migração, vem sendo questionada, sobretudo por conta do meio acadêmico. Por refugiado, que conta com todo um aparto jurídico específico, entenda-se aqui toda aquela pessoa que se enquadre na Convenção Internacional sobre o Estatuto dos Refugiados de 1951, incorporada pelo Brasil por meio da Lei no 9.474/97. Caso a pessoa não se enquadre como refugiado, será considerada, ao menos juridicamente, como migrante, sendo a ele aplicável o Estatuto do Estrangeiro de 1980, conforme ver-se-á mais adiante.

${ }^{15}$ ANISTIA INTERNACIONAL. Informe 2014/15: O Estado dos Direitos Humanos no Mundo.Trad.: Anistia Internacional Brasil. Londres: Ed. Amnesty International Ltd. Disponível em: <https://anistia.org.br/wpcontent/uploads/2015/02/Web-Informe-2015-03-06-final.pdf>. Acesso em: 20 set 2015.

${ }^{16}$ Idem, p. 37.

${ }^{17}$ Idem, p. 34.
}

Revista do Direito [ISSN 1982-9957]. Santa Cruz do Sul, v. 3, n. 50, p. 81-97, set./dez. 2016. https://online.unisc.br/seer/index.php/direito/index 
muros de fronteira e do apelo a soluções de punição e de repressão. Nesse sentido, novamente remetendo ao Informe da Anistia Internacionais, constatou-se que "entre outubro de 2013 e julho de 2014, 52.193 migrantes menores de idade desacompanhados foram detidos nos Estados Unidos, quase o dobro do número registrado nos 12 meses anteriores" ${ }^{18}$.

De outra banda, a fronteira de Foz do Iguaçu é exemplificativa da dinâmica territorial de política semi-periférica e, conforme estudos etnográficos realizados por Nogueira e Clemente, "marcada por contatos interculturais que permitem pensar hibridismo, interação social e relações interétnicas" ${ }^{\prime 1}$. Aqui, alerte-se que ao se falar em Tríplice Fronteira há de se compreender a delimitação existente entre Brasil (em Foz do Iguaçu), Argentina (em Puerto Iguaçu) e Paraguai (em Cuidad del Est e Presidente Franco).

Ora, ao abordar do tema da relação migratória na Tríplice Fronteira impossível não tratar dos diversificados aspectos culturais e questões do cotidiano (a exemplo maior da questão da segurança pública local) daquele que escolhe a região para melhor se estabelecer. Para tanto, é preciso compreender a simbiose da relação transfronteiriça e do migrante e, então, estudar os aspectos e desafios cotidianos deste.

\subsection{Fronteiras e o encontro com o outro}

Sobre as relações que as fronteiras consolidam em termos de reconhecimento e de encontro com o outro, configura-se um potencial de conflito muito mais intenso nos fluxos migratórios da periferia e da semi-periferia para os países centrais.

De outro vértice, no que diz respeito à fronteira dos países semiperiféricos, de que Foz do Iguaçu pode caracterizar um exemplo ilustrativo, o encontro entre pessoas contempla menos potencial conflitivo, o que não significa que estejam em causa processos suaves de construção de identidade.

Judith Batler já havia alertado para o potencial de conflito suscitado pelo encontro com o outro. A construção de uma relação de reconhecimento em que o conflito mantém baixa intensidade pode conduzir a duas perspectivas: o enfraquecimento das práticas comuns de reconhecimento ou a consideração pela singularidade do outro de que dependeria a construção da identidade ${ }^{20}$.

Em termos de reconhecimento do outro o que a Tríplice Fronteira de Foz do Iguaçu parece sugerir é, antes de mais nada, uma preocupação pela singularidade da pessoa, o que implicaria uma complexidade mais abrangente no processo de reconhecimento entre argentinos, brasileiros e paraguaios.

\subsection{Cultura de fronteira}

\footnotetext{
${ }^{18}$ Idem, p. 28.

${ }^{19}$ CLEMENTE, Claudelir Corrêa; NOGUEIRA, Barbara Freitas Ribeiro. Etnografia da Triplice Fronteira: Primeiras Aproximações. Revista Horizonte Científico (Uberlândia), v. 5, p. 1-21, 2011, p.6.

${ }^{20}$ BATLER, Judith. Precarious life: the powers of mourning and violence. Londres: Verso, 2006.
} 
Ainda que esse ensaio não pretenda uma discussão profunda a respeito da conceituação de cultura, de identidade ou mesmo de pluralismo, impossível não deixar de trazer uma noção do que seja cultura, uma vez que esta se mostra de especial relevo nas relações da Tríplice Fronteira e dos múltiplos olhares a ela conferidos. Dessa forma, para que não se tenha nenhuma lacuna quando no assunto cultura de fronteira, opta-se aqui por uma conceituação ampla de cultura, que leve em conta a diversidade de valores, espirituais e intelectuais e que leve em conta modos de viver. Inclusive, ressalte-se que em seara internacional, no âmbito da UNESCO, nos anos de 1980, foi realizada a Conferência Mundial Sobre Políticas Culturais, que declarou e optou por entender a cultura como "todo complexo material, espiritual, intelectual e emocional que caracteriza uma sociedade ou um grupo social" 21 .

Do mesmo modo, a noção de pluralismo deve ser vista, ao menos sob o ponto de vista ideológico, como um respeito e convívio à diferença do outro, sem deixar de levar em conta que deve tal conceito "ser visualizado tanto como fenômeno de possibilidades e dimensões de universalidade cultural, quanto como modelo que incorpora condicionantes inter-relacionados (formal e material), adequado às especificidades e condições históricas de micro e macro sociedades políticas"22.

Contudo, o pluralismo e a questão cultural ainda são objetos de luta cotidiana e de conflitos. Assim, por exemplo, sintetiza um dos dilemas envolvendo a cultura e identidade, Raimon Panikkar ${ }^{23}$.

“(...). Eu creio que a paisagem humana vista através de uma janela é, a um só tempo, semelhante e diferente da visão de outra. Se for o caso, deveríamos estilhaçar a janela e transformar os diversos portais em uma única abertura, com o conseqüente risco de colapso estrutural, ou deveríamos antes ampliar os pontos de vista tanto quanto possível, e acima de tudo, tornar as pessoas cientes de que existe, e deve existir, uma pluralidade de janelas?"

Nessa toada, no caso em tela a questão da cultura na fronteira parece suscitar, a priori, pelo menos duas perspectivas: a de que existe uma cultura comum na América Latina, que mesmo que diferenciada em relação a postulados básicos em um ou outro local teria um denominador comum, o que favoreceria projetos de integração social e de projetos de vida ou de que, ao revés, se trata de afirmar diferenças culturais em meio aos múltiplos anseios pessoas e sociais, dificilmente conciliáveis em última instância.

Pensar essas duas perspectivas conduz, ao seu turno, à outras duas premissas. A primeira é o incentivo de uma visão de sincretismo cultural. Na vida cotidiana, estampada por vários sinais, como por meio da literatura e da linguagem, tal sincretismo estaria presente, por exemplo, nas obras

\footnotetext{
${ }^{21}$ MONDIACULT 82, Conferência Mundial Sobre Políticas Culturais: Declaração do México, 1982, trad. livre. Disponível em: http://unesdoc.unesco.org/images/0005/000546/054668mb.pdf. Acesso em: 03 fev 2016.

${ }^{22}$ WOLKMER, Antônio Carlos. Pluralismo Jurídico. Fundamentos de uma nova cultura do Direito. São Paulo: Editora Alfa Ômega, 1994, p. 170.

${ }^{23}$ PANIKKAR, Raimon. Seria a noção de direitos humanos um conceito ocidental?, p. 205. In: BALDI, César Augusto (Org.). Direitos humanos na sociedade cosmopolita. Rio de Janeiro: Renovar, 2004.
} 
do paraguaio Augusto Roa Bastos, ou, no Brasil, nos romances de Érico Verissimo, ou ainda no projeto do argentino Xul Solar de uma língua "neocriolla", talvez o popularizado "portunhol".

Por sua vez, a segunda premissa parte de uma perspectiva que acentua as diferenças, enxerga nas manifestações culturais de cada país traços de uma singularidade que não pode ser reduzida a um denominador comum. Seria o sincretismo uma forma negativa de aculturação, sendo esta um processo decorrente da "fusão de duas ou mais culturas, que quando em contato contínuo, originam mudanças nos padrões culturais de ambos os grupos" ${ }^{24}$. Ou seja, partindo dessa visão o sincretismo seria considerado em seu sentido negativo, como "sinônimo de uma mistura confusa de elementos diferentes" 25 .

Entre uma perspectiva e outra, do ponto de vista antropológico pode ser interessante pensar o quanto o contato entre culturas na Tríplice Fronteira é capaz de influenciar uma dinâmica de mudanças, por exemplo, em termos de redução de desigualdades comuns à realidade brasileira, argentina e paraguaia, sem incorrer, no entanto, na noção diminuta da Tríplice Fronteira como local marcado por atividades escusas e pelo comércio ilegal, ou mesmo sem tomar a fusão de culturas diferentes em seu sentido pejorativo.

Com efeito, uma tomada de posição em torno das perspectivas em análise pode ter contribuído, ao longo da história, para romper ou levantar obstáculos a construção da socialidade no espaço da Tríplice Fronteira.

Esse conjunto de ideias em torno do território, do encontro com o outro e da interação de culturas, fornece elementos de compreensão da vida na Tríplice Fronteira, de modo a permitir estabelecer os fundamentos da normatividade dos direitos de cidadania na região.

\section{NO PLANO FÁTICO: A REALIDADE SOCIOECONÔMICA DA TRÍPLICE FRONTEIRA DE FOZ DO IGUAÇU}

Segundo os últimos dados do Instituto Brasileiro de Geografia e Estatística (IBGE), a região da Tríplice Fronteira abriga uma população superior a 500.000 pessoas, sendo que somente Foz do Iguaçu possuía 256.088 habitantes em $2010^{26}$ e hoje, por certo, conta com um número maior.

De maneira certeira, pode-se dizer que Foz do Iguaçu é uma cidade que vai além das reconhecidas belezas naturais e das fontes de energia, sendo que já foi alvo de intensas disputas políticas, como seria de se esperar, numa visão de geopolítica, em pontos estratégicos territoriais.

Conforme demonstrar-se-á nos próximos subtópicos, o arranjo urbano das cidades da Tríplice Fronteira está assentado, em grande medida, nos fluxos migratórios decorrentes de determinantes

\footnotetext{
${ }^{24}$ FERRETTI, Sérgio Figueiredo. Repensando o sincretismo. São Luís: FAPEMA, 1995, p. 45.

${ }^{25}$ Idem, p. 90. Vale salientar, conforme lembra o autor Ferretti, que o sincretismo não é ligado apenas à questão religiosa, como comumente se toma, mas também ocorre nos mais campos do cotidiano, como nas artes, na filosofia, na ciência, etc.

${ }^{26}$ INSTITUTO BRASILEIRO DE GEOGRAFIA E ESTATÍSTICA (IBGE). Arranjos Populacionais e Concentrações Urbanas no Brasil. Rio de Janeiro: Ministério do Planejamento, orçamento e gestão. Coordenação de Geografia do IBGE, 2015, p. 82. Disponível em:

$\mathrm{ftp}$ ://geoftp.ibge.gov.br/organizacao_territorial/arranjos_populacionais/arranjos_populacionais.pdf. Acesso em: 18 fev 2016.
} 
econômicas, sociais e étnicas. Essa realidade, contudo, não impediu a consolidação de uma convivência social em que respeitada a presença do outro, ainda que não isenta de conflitos.

\subsection{REALIDADE SOCIAL}

Os pesquisadores Ademir Luis Kinzler, Beatriz Koefender e Marines Orlandi, da Universidade do Oeste do Paraná (Unioeste), em estudo realizado sobre a realidade social da Tríplice Fronteira, identificaram o que eles denominam de "processos de enriquecimento cultural decorrente das relações sociais estabelecidas mediante o reconhecimento da alteridade do outro"27.

Segundo seus estudos, em Foz do Iguaçu, Ciudad del Este e Puerto Iguazu, não se verificam formas de segregação no contexto de convivência de várias culturas místicas com considerável número de católicos, árabes muçulmanos e protestantes. É comum, segundo os pesquisadores, observar a convivência de diferentes grupos de pessoas em escolas, na atividade comercial e nas organizações em geral, sem qualquer tipo de restrição; existe também nas cidades da Tríplice Fronteira um favorecimento ao intercâmbio entre o português e o espanhol, em que um e outro acaba sendo a segunda língua para crianças e jovens. Os pesquisadores sustentam que essa interação favorece uma prática local de globalização de difícil ocorrência em outros contextos sociais (Tríplice Fronteira e os Aspectos Culturais).

Ora, a interação de culturas diversas perpassa por meio de toda a grande e complexa máquina denominada de sociedade, e fornece seu panorama por meio de uma análise da realidade social, em que tudo e todos desempenham papéis fundamentais, mesmo que tais papéis não sejam facilmente identificáveis. Os sinais podem ser os mais diversos emitidos: as vestimentas, o uniforme, os móveis, as práticas comerciais, a comida, a linguagem utilizada, etc.

Contudo, para compreender a perspectiva social há de se analisar também a realidade econômica e problemas existentes. Nesse sentido, novamente retornando à noção de sistema, é preciso entender o todo para melhor solucionar questões.

\subsection{Realidade econômica}

Segundo dados, o Produto Interno Bruto Per Capita da região só de Foz do Iguaçu contabilizou, no ano de 2013, R\$37.483,00. Dos 256.088 habitantes da região, 133.547 fazem parte da população economicamente ativa (segundo dados de 2010), sendo que a renda média, em 2010, seria de $\mathrm{R} \$ 804,18$ por pessoa. O grau de urbanização da região também impressiona: $99,17 \%{ }^{28}$.

\footnotetext{
${ }^{27}$ KINZLER, Ademir Luis; KOEFENDER, Beatriz; ORLANDI, Marines. Tríplice Fronteira e os aspectos culturais. In: Trabalho de campo da disciplina: região e fronteira. Trabalho de mestrado- Unioeste, Setor de Ciências Humanas, Educação e Letras, Orientador Prof. Dr. Edson Belo Clemente de Souza, 2014.

${ }^{28}$ MINISTÉRIO PÚBLICO DO ESTADO DO PARANÁ (MPPR). Informações municipais para planejamento institucional. Versão 2.7, Município de Foz do Iguaçu, Janeiro de 2016. Disponível em: http://www2.mppr.mp.br/cid/foziguacu.pdf. Acesso em: 26 fev 2016.
} 
Do ponto de vista econômico e da integração regional, a Tríplice Fronteira também acaba sendo o vértice para onde converge a concretização do bloco econômico do Mercado Comum do Sul, doravante denominado de Mercosul. De todo modo, a percepção da consolidação de um mercado comum na região da Triplice Fronteira tem um registro local específico, na medida em que, nesse espaço, ao longo do tempo se intensificou toda uma atividade comercial e de serviços voltada para o turismo de compras; essa realidade econômica produziu efeitos no espaço terrritorial.

Conforme observam Cleunice Dias de Morais, Marcela Stuker e Vania Dirley Graff, pesquisadoras da Unioeste, a precarização do trabalho e os diferentes circuitos da economia capitalista incrementaram o comércio ambulante, o surgimento de pequenas empresas, e a prestação de serviços pessoais ${ }^{29}$. Segundo as pesquisadoras, a disputa pelo espaço nas cidades da Tríplice Fronteira operou-se em detrimento do convívio social e em benefício de atividades comerciais e de serviços que tomaram ruas e calçadas inviabilizando formas de planejamento urbano (A paisagem urbana na Triplice Fronteira) ${ }^{30}$.

Observa-se na Tríplice Fronteira a disputa pela produção social do espaço que evidencia o conflito que, de acordo com Mark Gottdiener, contrapõe interesses econômicos e interesses da cidadania $^{31}$.

O domínio do turismo de compras no espaço da Tríplice Fronteira, que mimetiza um sistema global de mercadorias, pode conduzir ao que David Harvey qualifica de contexto em que a colagem flexível da economia pós-moderna do já visto, do já comprado, do já ouvido, enfraquece o sentido do "outro", visto pela contingência do incremento do fragmentário, típico da "visita de turista" ${ }^{32}$.

Nos últimos anos, em Foz do Iguaçu observa-se uma mudança lenta nas finalidades do turismo local, com ênfase na exploração das belezas naturais das Cataratas do Iguaçu e seu entorno silvestre. Ao mesmo tempo, consolida-se o polo tecnológico, a partir do papel social e econômico da Itaipu Binacional, agora ampliado pela presença da Universidade da América Latina - Unila, que possui justamente o intento de contribuir com a integração latinoamericana e proporcionar a cooperação solidária com integrantes do Mercosul. Em Ciudad del Eeste a iniciativa é de construção de shoppings e de obras viárias de valorização do espaço público ao que parece na tentativa de redicionar os costumes de compras no local.

\subsection{A REALIDADE E A VIOLÊNCIA}

Não se pode esquecer, todavia, que Foz do Iguaçu tem índices de criminalidade elevados, que rivalizam com grandes cidades da região Sul, como a capital paranaense - Curitiba, e a cidade de Londrina, guardadas as devidas proporções.

\footnotetext{
${ }^{29}$ MORAIS, Cleunice Dias de; STUKER, Marcela; GRAFF, Vania Dirley. A paisagem urbana na Triplice Fronteira. In: Trabalho de campo da disciplina: região e fronteira. Trabalho de mestrado- Unioeste, Setor de Ciências Humanas, Educação e Letras, Orientador Prof. Dr. Edson Belo Clemente de Souza, 2014.

${ }^{30}$ Idem.

${ }^{31}$ GOTTDIENER, Mark. A produção social do espaço. 2. ad. São Paulo, EDUSP, 1997, p. 14 .

32 HARVEY, David. Condição pós-moderna: uma pesquisa sobre as origens da mudança cultural. Trad. de Adail Sobral e Maria Stela Gonçalves. São Paulo: Ed. Loyola, 16ạed., 2007, p. 271.
} 
O Ministério Público do Paraná (MPPR), em análise estratégica recente, analisou as ocorrências relativas à criminalidade, com enfoque para o combate ao crime de homicídio, verificando que de janeiro a setembro de 2015 foram constatadas 63 mortes decorrentes de homicídios dolosos. Não obstante, no mesmo período não se constataram mortes decorrentes de latrocínio (roubo com resultado morte) ou casos de lesão corporal com resultado morte. Outras causas para mortes que o MPPR verificou seriam advindas de acidentes de transporte e, em menor escala, por suicídios ${ }^{33}$.

Outros crimes também possuem alta taxa de ocorrências policiais na região, como furto e roubo, corrupção de menores, violência doméstica, estupro, posse e tráfico de drogas, etc. Em matéria de segurança pública, a região de Foz do Iguaçu não conta com um Plano de Segurança Pública ou um Fundo Municipal de Segurança ${ }^{34}$.

Essa realidade pode contribuir para a consolidação de fronteiras territoriais dentro da própria cidade, reproduzindo, em certo sentido, a tensão de coexistência que Gabriel de Santis Feltran enxerga na sociedade brasileira, entre uma perspectiva universalista e, por isso, formal, de democracia, e uma perspectiva instrumental da violência que opera em uma dinâmica de distribuição dos lugares sociais marcada por extrema hierarquização ${ }^{35}$. Em outras palavras: é como se existisse um direito que não fosse estatal, um direito das ruas, fora da formalidade da lei, mas regrada por normativas criadas em prol da sobrevivência.

Nesse vértice, opera-se na Triplice Fronteira uma dinâmica social paradoxal extraestatal que favorece a integração de pessoas de diferentes culturas em que, ao mesmo tempo em que reconstrói fronteiras sociais e econômicas, recortam o espaço e a dinâmica de construção da socialidade.

Diante dessa conjuntura, resta verificar o modo como o Direito responde a essa dinâmica em termos de normatividade dos direitos de proteção da pessoa e da cidadania.

\section{RECONHECIMENTO, DIGNIDADE E DIREITOS DE CIDADANIA NA FRONTEIRA}

O migrante que ingressa no Brasil possui sua condição jurídica estabelecida por meio de matéria constitucional e também pela Lei n. ${ }^{\circ} 6.815 / 1980$, chamada comumente de Estatuto do Estrangeiro.

Segundo a Constituição Brasileira de 1988, por meio de seu artigo 5, caput, os estrangeiros residentes no Brasil possuem os mesmos direitos fundamentais que aqueles garantidos aos nacionais $^{36}$. Acrescida a esta proteção constitucional, o Estatuto do Estrangeiro serve para melhor regulamentar os direitos e garantias do estrangeiro, além de estabelecer mecanismos de entrada, permanência e saída do estrangeiro no território brasileiro, em conformidade aos requisitos

\footnotetext{
${ }^{33}$ MINISTÉRIO PÚBLICO DO ESTADO DO PARANÁ (MPPR) Informações municipais para planejamento institucional. Versão 2.7, Município de Foz do Iguaçu, Janeiro de 2016, p. 31. Disponível em: http://www2.mppr.mp.br/cid/foziguacu.pdf. Acesso em: 26 fev 2016.

${ }^{34}$ Idem, p. 28.

${ }^{35}$ FELTRAN, Gabriel de Santis. Fronteiras de tensão: política e violência nas periferias de São Paulo. São Paulo: Editora UNESP, 2011.

${ }^{36}$ BRASIL. Constituição da República Federativa do Brasil. Brasília: Senado, 1988.
} 
estabelecidos na lei e com fulcro na noção maior de soberania brasileira, ou seja, na observância dos interesses soberanos da República Federativa do Brasil ${ }^{37}$.

De outra banda, muitas transformações ocorreram de 1980 até os dias de hoje, especialmente quando se trata do tema migração. Ora, todo estrangeiro, ou melhor, toda pessoa, possui o direito de migrar.

No ponto, a noção de direito de migrar não é propriamente uma ideia nova e atual, mas que remanesce como um desafio e como um enfrentamento ao pensamento vestefaliano de soberania dos Estados que parece permanecer até os dias atuais ${ }^{38}$.

Assim, atualmente já há variados documentos internacionais que expressam o direito de migrar. No âmbito das Nações Unidas, o mais significativo documento sobre o tema é a Convenção internacional sobre proteção dos direitos de todos os trabalhadores migrantes (ainda em tramitação para ingresso no ordenamento jurídico brasileiro), sem contar que antes já a sociedade internacionais estampava a necessidade de garantir direitos aos migrantes, como constatado por meio da Convenção de Havana sobre a condição dos estrangeiros, recepcionada no Brasil por meio do Decreto n. $18.871^{39}$, entre outros tratados internacionais.

Para além desses importantes documentos internacionais, a jurisprudência regional, em matéria de Direitos Humanos, também parece volver os olhos a uma retomada da noção de jus gentium. Para exemplificar, pode-se citar o caso comentado por Cançado Trindade, dos "migrantes indocumentados" e o posicionamento da Corte Interamericana de proteção aos direitos humanos, a qual clarificou que o tratamento desigual que discrimine o migrante gera responsabilização internacional, sendo que cada Estado deve se atentar para melhor garantir direitos como o do acesso à justiça, à vida privada, entre tantos outros. A Corte ainda ressaltou que aos migrantes deve ser tomada uma posição mais holística, mais ampliada, de forma a não deixar nenhum ser humano sem proteção jurídica ${ }^{40}$.

Ademais, além das questões de fundo teórico, hodiernamente a realidade socioeconômica, especialmente de locais estratégicos como a Tríplice Fronteira, muitas vezes sobrepõem-se ao Direito, ou, ainda, é relegada pelo Estado por não se enquadrar nos requisitos estabelecidos no

\footnotetext{
${ }^{37}$ BRASIL. Lei n.o 6.815. Define a situação jurídica do estrangeiro no Brasil, cria o Conselho Nacional de Imigração. Brasília: Presidência da República, 1980.

${ }^{38}$ De forma sumária, tem-se que os chamados Tratados de Vestefália foram uma série de tratados que deram ensejo à chamada Paz de Vestefália, em 1648, que pôs fim à Guerra dos Trinta dos Anos e foi essencial ao Direito Internacional e ao Direito Interno, porquanto delimitou o conceito de soberania dos Estados, a noção de diplomacia e determinou a autoridade do Estado (ilustrado por meio da figura do Monarca) em detrimento do poder da Igreja. Por isso mesmo, ao se afirmar que a visão vestefaliana deve ser analisada e vencida nos dias atuais, significa estabelecer um novo olhar à noção de soberania dos Estados. Não obstante, a ideia de um direito de migrar já é suscitada desde há muito, a exemplo dos ensinamentos de Francisco de Vitoria, segundo o qual haveria de se ter um constitucionalismo mundial, em prol da garantia do jus communicationis (direito de se comunicar), do direito de viajar e do direito de se estabelecer em terras distintas. Nesse sentido, vide: FERRAJOLI, Luigi. A soberania no mundo moderno. Nascimento e crise do Estado nacional. Trad. Carlos Coccioli, Márcio Lauria Filho e Karina Jannini. São Paulo: Ed. Martins Fonte, 2002.

${ }^{39}$ BRASIL. Decreto n. 18.871. Promulga a Convenção de direito internacional privado, de Havana.Rio de Janeiro: Presidência, 1929.

${ }^{40}$ TRINDADE, Antônio Augusto Cançado. A humanização do direito internacional. Belo Horizonte: Del Rey, 2006, p. 310.
} 
Estatuto do Estrangeiro, conforme vislumbrado acima. No mais, acrescente-se à complicada questão jurídica do refúgio, limitada a apenas determinados candidatos.

Dessa forma, o Estatuto do Estrangeiro de 1980 não se revela mais adequado para a regulação dos problemas decorrentes das novas relações de fronteira e de migração.

Para tanto, o Ministério da Justiça, por meio da Portaria n. ${ }^{\circ}$ 2162/2013, se mobilizou e criou uma comissão de especialistas encarregada de elaborar o projeto da Lei de Migrações e de Promoção dos Direitos dos Migrantes do Brasil ${ }^{41}$.

A última versão do Anteprojeto da Lei de Migrações apoia-se em um conjunto de princípios protetores dos direitos humanos dos migrantes que, segundo os formuladores do projeto, estaria em linha com o propósito da Constituição da República de construção de uma sociedade justa e solidária. O referido Anteprojeto de Lei de Migração também está inspirado na Convenção Internacional sobre proteção dos direitos de todos os trabalhadores migrantes e dos membros de suas famílias de 1990.

Especificamente em relação aos residentes na fronteira, o Anteprojeto da Lei de Migrações assegura o direito ao trabalho e à frequência à escola pública ou privada. Não obnstante, o art. 58 da Convenção internacional sobre proteção dos direitos de todos os trabalhadores migrantes é mais abrangente e assegura ao trabalhador fronteiriço o direito ao trabalho, ao serviço de saúde, à escola, à habitação e à vida cultural ${ }^{42}$.

Na Argentina, a Lei n. ${ }^{0} 25.871$ de janeiro de 2004 (Ley de migraciones) protege o trabalhador fronteiriço com direitos semelhantes ao que consta da Convenção internacional sobre a proteção dos direitos de todos os trabalhadores migrantes e chega a ser mais avançada do que o Anteprojeto da Lei de Migrações brasileira ${ }^{43}$.

A questão que deve ser colocada é se, considerada a realidade socioeconômica e cultural consolidada, no contexto da Tríplice Fronteira a positivação de uma lei de proteção das migrações, apoiada nos princípios dos direitos humanos, é capaz de assegurar vida digna à pessoa do migrante.

Do ponto de vista jurídico essa questão pode ser analisada sob duas perspectivas: a do alcance da normatividade dos direitos humanos e a da questão do reconhecimento. É o que ver-se-á, ainda que de maneira sumária, nos próximos subtópicos.

\subsection{Alcance da normatividade dos direitos humanos dos migrantes}

Conforme afirmado por Francisco C. Oliveira e Adeilson Luz Oliveira, a positivação dos direitos humanos nas declarações e nas constituições não dissipa o potencial de distopia que possa

\footnotetext{
${ }^{41}$ MINISTÉRIO DA JUSTIÇA, Comissão de Especialistas. Anteprojeto de lei de migrações e promoção dos direitos dos migrantes no Brasil. Brasília: Comissão de Especialistas do Ministério da Justiça, 2014. Disponível em: http://library.fes.de/pdf-files/bueros/brasilien/10947.pdf. Acesso em: 28 fev 2016.

${ }^{42}$ NAÇÕES UNIDAS. Convenção Internacional sobre a Proteção dos Direitos de Todos os Trabalhadores Migrantes e dos Membros das suas Famílias. Assembléia Geral das Nações Unidas, 1990.

${ }^{43}$ ARGENTINA. Ley 25.871. Senado, Camara Diputados de la Nación Argentina: Buenos Aires, 2004.
} 
estar arraigado na forma de organização da estrutura social ${ }^{44}$. Observa-se uma tendência de universalidade abstrata e de idealismo que cerca a juridicização dos direitos humanos.

Assim, por direitos humanos há de se entendido, aqui, como "os processos, as dinâmicas de lutas históricas decorrentes de resistências contra a violência que as diferentes manifestações do poder do capital exerceram contra os indivíduos e coletivos" $"$.

Enquanto a realidade não permite assimilar modos de vida humanizados, os direitos humanos constituem fórmulas abstratas sem força para modificar a vida em sociedade. Daí a necessidade de contínua reconstrução dos direitos humanos, no contexto histórico das sociedades liberais democráticas.

Ademais, as crises sociais e econômicas engendradas pelo modelo de economia de mercado dominante nas democracias liberais, a exemplo do que está a ocorrer com a crise financeira desde 2008, alimenta a necessidade de contínua reconstrução dos direitos humanos.

Em relação aos direitos humanos manifesta-se um paradoxo: a positivação dos direitos emerge de uma realidade violenta ao mesmo tempo em que a simples positivação não assegura efetividade aos direitos. Na questão dos direitos humanos evidencia-se com toda força o caráter material da normatividade que não se restringe ao formalismo do sistema jurídico de regras e princípios.

Desse modo, ancorar a legislação protetora do migrante no principismo dos direitos humanos pode não significar muito. Pode ser apenas o começo de uma normatividade que exigirá uma trama de lutas por efetividade e reconhecimento de direitos.

\subsection{Pressupostos do reconhecimento de direitos dos migrantes}

A exemplo do que ocorre com outras espécies de direitos, a normatividade dos direitos do migrante está sujeita ao conflito inerente à luta por reconhecimento de direitos.

Veja-se que, inclusive, o art. 28 da Convenção internacional sobre a proteção dos direitos de todos os trabalhadores migrantes afirma que todo o trabalhador migrante tem direito ao reconhecimento como pessoa, perante a lei ${ }^{46}$.

O problema do reconhecimento de direitos, de acordo com Axel Honneth, tem como pressuposto a formulação de Hegel de que a constituição da pessoa ocorre nos termos de uma luta por reconhecimento de direitos, que pressupõe o conflito entre sujeitos no contexto da vida social ${ }^{47}$.

No ponto, mais recentemente Axel Honneth busca recuperar, nas ideias de Hegel sobre o direito $^{48}$, aquilo que Ricardo Crissiuma qualifica de substituição da busca pela experiência do

\footnotetext{
${ }^{44}$ OLIVEIRA, Francisco Cardozo; OLIVEIRA, Adeilson Luz. Paradoxos e utopia na normatividade dos direitos humanos: a efetividade da proteção da pessoa e da cidadania na perspectiva material das relações de reconhecimento. In: Direitos humanos e direitos internacionais. CONPEDI/Florianópolis, 2014.

${ }^{45}$ FLORES, Joaquim Herrera; A (re)invenção dos direitos humanos. Florianópolis: Fundação Boiteux, 2009, p. 169.

${ }^{46}$ NAÇÕES UNIDAS. Convenção Internacional sobre a Proteção dos Direitos de Todos os Trabalhadores Migrantes e dos Membros das suas Famílias. Assembléia Geral das Nações Unidas, 1990.

${ }^{47}$ HONNETH, Axel. Sofrimento por indeterminação: uma reatualização da Filosofia do direito de Hegel. São Paulo: Editora Singular, 2007.
} 
reconhecimento por meio da estrutura intersubjetiva da identidade pessoal, fundada numa antropologia filosófico-naturalista, pela busca das expectativas subjetivas de reconhecimento e dos discursos de justificação em meio às práticas sociais ${ }^{49}$; coloca-se em causa, desse modo, o caráter social e histórico da luta por reconhecimento de direitos.

É nesse sentido, portanto, de uma luta por reconhecimento de direitos, em meio às práticas sociais, que deve ser identificada a normatividade dos direitos dos migrantes, de modo que a realidade da Triplice Fronteira deve ser vislumbrada como uma prática social de efetividade dos direitos dos migrantes pelo enfrentamento e superação dos desafios em termos de proteção da dignidade da pessoa.

Para além dos estatutos, a proteção da pessoa do migrante se efetiva a partir da luta por reconhecimento de direitos na realidade social. A Tríplice Fronteira, nesse sentido, constitui um dos lugares privilegiados de desdobramento dessa luta que não pode ser negligenciado por aqueles que, na América Latina, estão comprometidos com o combate a todas as formas de injustiça.

\section{CONSIDERAÇÕES FINAIS}

Ante todo o exposto, duas ideias centrais foram explanadas, quais sejam: (a) a normatividade dos direitos de cidadania na região da Triplice Fronteira deve considerar os desdobramentos da realidade socioeconômica, das relações sociais no território, do encontro com o outro e da interação de culturas, sem que a fusão, a mistura de relações, de visões e de sinais seja visto como algo negativo; (b) a proteção dos direitos de cidadania das pessoas na Triplice Fronteira se desdobra a partir da configuração material dos conflitos em torno da luta por reconhecimento de direitos de migrantes.

Para realizar o encontro com essas ideias centrais, variadas vertentes do saber foram utilizadas, a fim de formar uma visão holística e ampla da migração, da cidadania e de sua relação com o Direito. Para tratar do tema, pois, reconhecida foi a importância de estudos por áreas da Antropologia, da Geopolítica, das Relações Internacionais e da Economia.

Ora, a proteção da cidadania e das migrações na fronteira depende muito mais da consideração da realidade da luta por reconhecimento de direitos do que dos termos abstratos da lei positiva, ainda que, claro, a existência da lei ela mesma faça parte do contexto histórico e detenha sua importância.

Por certo, buscar a legitimidade desses migrantes e povos, especialmente por meio de um novo olhar à normatividade jurídica, é algo que o espaço acadêmico brasileiro deve aperfeiçoar constantemente, sem criar, contudo, um insulamento e ficar adstrito apenas ao plano teórico.

Numa visão holística, a luta por reconhecimento na fronteira se revela no horizonte paradigmático de encontro com o outro, dos termos do conflito de que emergem possibilidades de

\footnotetext{
${ }^{48}$ HONNETH, Axel.Sofrimento por indeterminação: uma reatualização da Filosofia do direito de Hegel, São Paulo: Editora Singular, 2007.

${ }^{49}$ CRISSIUMA, Ricardo. Trocando o jovem pelo velho: Axel Honneth leitor de Hegel. In A teoria crítica de Axel Honneth: reconhecimento, liberdade e justiça. MELO, Rúrion (Coord.) São Paulo, Editora Saraiva, 2013.
} 
emancipação, não apenas para aqueles que vivem na Tríplice Fronteira, mas para todos aqueles em que a injustiça se inscreve na vida em sociedade como barreiras, muros e fronteiras.

\section{REFERÊNCIAS}

ANISTIA INTERNACIONAL. Informe 2014/15: O Estado dos Direitos Humanos no Mundo.Trad.: Anistia Internacional Brasil. Londres: Ed. Amnesty International Ltd. Disponível em: <https://anistia.org.br/wp-content/uploads/2015/02/Web-Informe-2015-03-06-final.pdf>. Acesso em: 20 set 2015 .

ARGENTINA. Ley 25.871. Senado, Camara Diputados de la Nación Argentina: Buenos Aires, 2004.

BATLER, Judith. Precarious life: the powers of mourning and violence. Londres: Verso, 2006.

BRASIL. Constituição da República Federativa do Brasil. Brasília, DF: Senado, 1988.

Decreto n. $^{\circ}$ 18.871. Promulga a Convenção de direito internacional privado, de Havana. Rio de Janeiro: Presidência, 1929.

. Lei n. $^{\circ}$ 6.815. Define a situação jurídica do estrangeiro no Brasil, cria o Conselho Nacional de Imigração. Brasília: Presidência da República, 1980.

CAIRO, Heriberto. A América Latina nos modelos geopolíticos modernos: da marginalização à preocupação com sua autonomia. Caderno CRH, vol.21, n.53 Salvador Mai/Ago 2008. Disponível em: http://dx.doi.org/10.1590/S0103-49792008000200003. Acesso em: 02 fev 2016.

CLEMENTE, Claudelir Corrêa; NOGUEIRA, Barbara Freitas Ribeiro. Etnografia da Triplice Fronteira: Primeiras Aproximações. Revista Horizonte Científico (Uberlândia), v. 5, p. 1-21, 2011

CORSINI, Leonora. Fronteiras, atravessamentos e deslocamentos: desenhando novas cidadanias. In Fronteiras e diversidades culturais no século XXI: desafios para o reconhecimento no estado global. Maciel, Tania Barros; Neto, Maria Inácia Davila; Andrade, Regina Glória(Org), FAPERJ, Rio de Janeiro, 2012.

CRISSIUMA, Ricardo. Trocando o jovem pelo velho: Axel Honneth leitor de Hegel. In A teoria crítica de Axel Honneth: reconhecimento, liberdade e justiça. MELO, Rúrion (Coord.) São Paulo, Editora Saraiva, 2013.

FALK, Richard. Globalização Predatória: uma crítica. Trad. de Rogério Alves. Lisboa: Instituto Piaget, 1999.

FELTRAN, Gabriel de Santis. Fronteiras de tensão: política e violência nas periferias de São Paulo. São Paulo: Editora UNESP, 2011. 
GOTTDIENER, Mark. A produção social do espaço. 2. ad. São Paulo, EDUSP, 1997.

HARVEY, David. A condição pós-moderna. São Paulo, Edições Loyola, 2008.

FERRAJOLI, Luigi. A soberania no mundo moderno. Nascimento e crise do Estado nacional. Trad. Carlos Coccioli, Márcio Lauria Filho e Karina Jannini. São Paulo: Ed. Martins Fonte, 2002.

FERRETTI, Sérgio Figueiredo. Repensando o sincretismo. São Luís: FAPEMA, 1995.

FLORES, Joaquim Herrera; A (re)invenção dos direitos humanos. Florianópolis: Fundação Boiteux, 2009.

HANNERZ, Ulf. Fluxos, Fronteiras, Híbridos: palavras-chave da antropologia transnacional. Mana Estudos de Antropologia Social, vol. 3, n. 1.Rio de Janeiro, Contracapa, abril, p. 07-39, 1997.

HARVEY, David. Condição pós-moderna: uma pesquisa sobre as origens da mudança cultural. Trad. de Adail Sobral e Maria Stela Gonçalves. São Paulo: Ed. Loyola, 16ªed., 2007, p. 271.

HONNETH, Axel. Luta por reconhecimento -a gramática moral dos conflitos sociais. São Paulo, Editora 24, 2003.

Sofrimento por indeterminação: uma reatualização da Filosofia do direito de Hegel, São Paulo: Editora Singular, 2007.

INSTITUTO BRASILEIRO DE GEOGRAFIA E ESTATÍSTICA (IBGE). Arranjos Populacionais e Concentrações Urbanas no Brasil. Rio de Janeiro: Ministério do Planejamento, orçamento e gestão. Coordenação de Geografia do IBGE, 2015, p. 82. Disponível em:

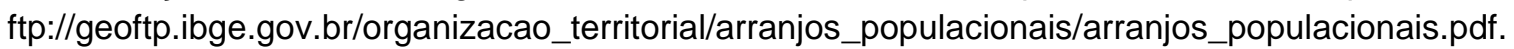

Acesso em: 18 fev 2016.

KINZLER, Ademir Luis; KOEFENDER, Beatriz; ORLANDI, Marines. Tríplice Fronteira e os aspectos culturais. In: Trabalho de campo da disciplina: região e fronteira. Trabalho de mestrado- Unioeste, Setor de Ciências Humanas, Educação e Letras, Orientador Prof. Dr. Edson Belo Clemente de Souza, 2014.

MINISTÉRIO DA JUSTIÇA, Comissão de Especialistas. Anteprojeto de lei de migrações e promoção dos direitos dos migrantes no Brasil. Brasília: Comissão de Especialistas do Ministério da Justiça, 2014. Disponível em: http://library.fes.de/pdf-files/bueros/brasilien/10947.pdf. Acesso em: 28 fev 2016.

MINISTÉRIO PÚBLICO DO ESTADO DO PARANÁ (MPPR). Informações municipais para planejamento institucional. Versão 2.7, Município de Foz do Iguaçu, Janeiro de 2016. Disponível em: http://www2.mppr.mp.br/cid/foziguacu.pdf. Acesso em: 26 fev 2016. 
MONDIACULT 82, Conferência Mundial Sobre Políticas Culturais: Declaração do México, 1982, trad. livre. Disponível em: http://unesdoc.unesco.org/images/0005/000546/054668mb.pdf. Acesso em: 03 fev 2016.

MORAIS, Cleunice Dias de; STUKER, Marcela; GRAFF, Vania Dirley. A paisagem urbana na Triplice Fronteira. In: Trabalho de campo da disciplina: região e fronteira. Trabalho de mestradoUnioeste, Setor de Ciências Humanas, Educação e Letras, Orientador Prof. Dr. Edson Belo Clemente de Souza, 2014.

NAÇÕES UNIDAS. Convenção Internacional sobre a Proteção dos Direitos de Todos os Trabalhadores Migrantes e dos Membros das suas Famílias. Assembléia Geral das Nações Unidas, 1990.

OLIVEIRA, Francisco Cardozo; OLIVEIRA, Adeilson Luz. Paradoxos e utopia na normatividade dos direitos humanos: a efetividade da proteção da pessoa e da cidadania na perspectiva material das relações de reconhecimento. In: Direitos humanos e direitos internacionais. CONPEDI/Florianópolis, 2014.

PANIKKAR, Raimon. Seria a noção de direitos humanos um conceito ocidental?, p. 205. In: BALDI, César Augusto (Org.). Direitos humanos na sociedade cosmopolita. Rio de Janeiro: Renovar, 2004.

SANTOS, Milton. Natureza do espaço; técnica e tempo, razão e emoção. 3. ${ }^{a}$ ed., São Paulo, Hucitec. 1999.

TRINDADE, Antônio Augusto Cançado. A humanização do direito internacional. Belo Horizonte: Del Rey, 2006.

WALLERSTEIN, Immanuel. The modern World-System: capitalist Agriculture and the origins of the european World-Economy in the sixteenth century. Nova York. Academic Press, 1974.

WOLKMER, Antônio Carlos. Pluralismo Jurídico. Fundamentos de uma nova cultura do Direito. São Paulo: Editora Alfa Ômega, 1994.

\section{COMO CITAR ESSE DOCUMENTO:}

CARDOZO OLIVEIRA, Francisco; BIACCHI GOMES, Eduardo; BRANDALISE GONÇALVES, Ane Elise. Migração, cidadania e direitos fundamentais na tríplice fronteira. Revista do Direito, Santa Cruz do Sul, v. 3, n. 50, p. 81-97, set. 2016. ISSN 1982-9957. Disponível em: <https://online.unisc.br/seer/index.php/direito/article/view/8411>. Acesso em: doi:http://dx.doi.org/10.17058/rdunisc.v3i50.8411. 